East African Medical Journal Vol. 85 No. 6 June 2008

ENVIRONMENTAL AND OCCUPATIONAL EXPOSURE TO LEAD

G.K. Njoroge, MSc (Medical Biochem.), Department of Laboratory Medicine, Intensive Care Unit, Kenyatta National Hospital, P.O. Box 20723, Nairobi, Kenya and Department of Biochemistry and Biotechnology, Kenyatta University, E.N.M. Njagi, PhD, Associate Professor, G.O. Orinda, PhD, Lecturer, Department of Biochemistry and Biotechnology, School of Pure and Applied Sciences, Kenyatta University, P.O. Box 43844, Nairobi, Kenya, C.B. Sekadde-Kigondu, PhD., Associate Professor, Department of Human Pathology and J.K. Kayima, MBChB, MMed (Internal Med.), Senior Lecturer, Department of Medicine, College of Health Sciences, University of Nairobi, P.O. Box 19676-00202, Nairobi, Kenya

Request for reprints to: Mr. G.K. Njoroge, P.O. Box 1711-00902, Kikuyu, Kiambu, Kenya

\title{
ENVIRONMENTAL AND OCCUPATIONAL EXPOSURE TO LEAD
}

\author{
G.K. NJOROGE, E.N.M. NJAGI, G.O. ORINDA, C.B. SEKADDE-KIGONDU and J.K. KAYIMA
}

\begin{abstract}
Objective: To determine the status of environmental and occupational lead exposure in selected areas in Nairobi, Kenya.

Design: Cross sectional study.

Setting: Kariobangi North, Babadogo, Waithaka and Pumwani for assessment of environmental exposure to lead $(\mathrm{Pb})$ and Ziwani Jua Kali works for assessment of occupational lead exposure. Olkalou in Nyandarua District was the covariate study area.

Subjects: Three hundred and eight children and adults participated.

Results: Blood lead levels (BLLs) obtained for the entire sample $(\mathrm{n}=308)$ ranged from 0.4 to $65 \mu \mathrm{g} /$ dl of blood. One hundred and sixty nine (55\%) of the total sample had levels equal to or below $4.9 \mu \mathrm{g} / \mathrm{dl}$, while $62(20 \%)$ of the sample had levels ranging from 5.0 to $9.9 \mu \mathrm{g} / \mathrm{dl}$. Blood lead levels above $10 \mu \mathrm{g} / \mathrm{dl}$ were recorded in $77(25 \%)$ of the total sample. Within Nairobi, $32(15.3 \%)$ of the study subjects in areas meant for assessment of environmental lead exposure had levels above the WHO/CDC action levels of $10 \mu \mathrm{g} / \mathrm{dl}$ of blood. The mean BLL for the occupationally exposed (Ziwani Jua kali) was $22.6 \pm 13.4 \mu \mathrm{g} / \mathrm{dl}$. Among the workers, $89 \%$ had BLLs above $10 \mu \mathrm{g} / \mathrm{dl}$. In general, $15 \%$ of the entire sample (for both environmental and occupational groups) in Nairobi had BLLs above $15 \mu \mathrm{g} / \mathrm{dl}$. The covariate group at Olkalou had a mean BLL of $1.3 \pm 0.9 \mu \mathrm{g} / \mathrm{dl}$.

Conclusion: The prevalence of environmental lead exposure to the general public is high in Nairobi compared to Olkalou where non exposure was reported. Occupational lead exposure has been identified to be at alarming levels and urgent intervention measures are recommended.
\end{abstract}

\section{INTRODUCTION}

Lead is a naturally occurring element, the most accessible of the heavy metals in the earth's crust that is widely distributed and used in numerous industrial processes and domestic appliances (1). Human uptake of this non-essential element causes cumulative toxicity that affects multiple systems and organs in the human body. Although a lot of focus has been directed towards occupational exposure, concern has grown over the possible adverse effects due to chronic exposure to low levels of lead in the environment $(2,3)$. Depending on whether lead exposure is acute or chronic, serious physiologic effects, including death or long-term irreversible damage to brain function and organ systems occur. Lead primarily affects the peripheral and central nervous systems, renal function, haematopoietic system, and the metabolism of vitamin D and calcium. Lead also causes hypertension, reproductive toxicity, and developmental effects $(1,2)$. Lead intoxication is dangerous to all people in all sectors but children are more vulnerable due to their lifestyle, rapid growth and still developing systems. 
Older persons have higher deposition in the kidneys due to renal insufficiency as age advances $(4,5)$. The $\mathrm{WHO}(6)$ estimates indicate that 12 million children in developing countries suffer from some form of permanent brain damage due to lead poisoning. All over the world, about $3.5 \%$ of minor mental retardations are attributable to lead poisoning.

Globally, most of the lead found throughout the environment has been attributed to the use of leaded gasoline (7). Other sources of lead include industrial emissions, burning of solid waste containing plastics or painted wood, burning candle wicks, some cosmetics, cigarettes, and dust from lead painted surfaces. Vegetables, grains and fruits exposed to heavy vehicle exhaust or industrial emissions may also contain higher than normal concentrations of lead. Lead may also be ingested in illicitly distilled whiskies and from water whose delivery system is mainly made up of leaded pipes $(1,6)$. Occupationally, people who work in lead smelting and refining industries and those who deal with lead during the manufacturing process as well as policemen who stand for long hours in traffic may be overexposed to lead. Construction workers and people who work at municipal waste incinerators, pottery and ceramic industries and radiator repair shops could all be exposed to high lead levels $(1,3)$.

The major routes of lead entry into the human body are inhalation and ingestion and to a lesser extent through dermal absorption (8-10). Inhaled lead particles are deposited in the respiratory tract depending on their sizes, breathing patterns (e.g., nose breathing vs. mouth breathing) which are age related, airway geometry and air movement within the respiratory tract. Absorption of lead from the gastrointestinal tract is primarily in the duodenum and depends on the chemical form ingested, age, meal status and nutritional factors. The less calcium or iron there is in the diet, the more of lead that is absorbed. Adult human absorb about $10-20 \%$ of ingested lead, whereas children absorb up to $70 \%$ of ingested lead $(1,10)$.

Lead absorbed from the respiratory or intestinal tract is bound to several intracellular proteins within erythrocytes. The absorbed lead is further distributed to other compartments such as kidney, liver, muscle, the gonads and bone. The half-life of bone lead is more than twenty years while its half-life in blood is 25-28 days $(1,10)$. Organic lead is biotransformed in the liver through a P-450 mediated oxidative dealkylation to highly neurotoxic metabolites or completely oxidized to inorganic lead. Inorganic lead forms reversible complexes with amino acids and non-protein thiols, conjugated to glutathione and excreted primarily in the urine. Lesser amounts are excreted through sweat, skin hair, nails, bile and breast milk. In patients with high bone lead burden, slow release from the skeleton may elevate blood lead concentration for years after exposure ceases $(1,10)$. The biochemical basis for the multiple toxic effects of lead is its ability to form complexes with ligands such as sulphate, carboxylic and the imidazole groups of proteins and interact with the function of enzymes, signal systems and membranes $(1,2,10)$.

Exposure to lead is usually characterised by subtle, non-specific symptoms that frequently contribute to misdiagnosis of lead poisoning and the onset of symptoms depend on whether the intoxication was acute or chronic (1). The concentration of lead in whole blood is frequently used to diagnose and monitor exposure to lead and is considered to be the most reliable biomarker for general clinical use and public health surveillance. The higher the test result, the more lead in the system and the more potential danger there is to health $(1,7)$. Although the WHO and the United States Centers for Disease Control (CDC) defined blood lead levels of $10 \mu \mathrm{g} / \mathrm{dl}$ of blood as toxic in 1991, no safe levels have been established as effects have been observed even at lower levels and action is being taken to reduce the international accepted levels of action (11-13).

This paper presents the findings of a study conducted to determine the status of general public and occupational lead exposure in Nairobi and provide baseline blood lead levels as a reference in evaluation of lead poisoning in Nairobi.

\section{MATERIALS AND METHODS}

The study area/study population: This was a crosssectional analytical study on blood lead levels conducted in Kariobangi North, Babadogo, Waithaka, and Pumwani to establish environmental exposure in Nairobi and the Ziwani Jua kali engineering works for evaluation of occupational exposure. Olkalou in Nyandarua district was the covariate study site. Subjects of study were randomly selected in health care facilities, an informal school at Pumwani and a designated work place at Ziwani. A questionnaire was 
administered to obtain information on age, sex, place of residence, occupation and health status of participating individuals. Very sick patients, those with chronic illness, renal failure or conditions predisposing to renal insufficiency were excluded from the study. Blood lead levels were determined in a total of 308 study subjects. Children and adolescents (ages $\leq 20$ years) made up $40.9 \%$ of the study population.

Collection and testing of blood samples: Blood samples were obtained from all participating individuals by finger pricking and collected in heparinised capillary tubes. Fifty microliter of the blood sample was transferred into an acid based treatment reagent for preanalytical sample preparation. Analysis of the sample for BLLs determination was done based on Anodic Stripping Voltammetry (ASV) using a portable LeadCare ${ }^{\circledR}$ Blood Lead Testing System and LeadCare® Blood Lead Testing Kits manufactured by ESA of Chelmsford, USA following the methodology detailed in the users manual (14). The blood lead concentrations were reported in micrograms per deciliter of blood $(\mu \mathrm{g} / \mathrm{dl})$.

Statistical analysis: Principal goals of the statistical analysis were to compare the blood lead levels obtained in the different study areas in Nairobi and Olkalou. Data collected by questionnaire and all blood lead levels obtained was coded using epi-info.v.6.0 software. Statistical analysis was done using Graphpad instant ${ }^{\mathrm{TM}}$ version 2.04. ANOVA, post ANOVA Tukey Kramer and Dunn's multiple comparison tests and unpaired t-test were used to compare associations between and within study areas. $\mathrm{P}<0.05$ was considered to be significant variation in BLLs between comparisons at 95\% confidence limit.

\section{RESULTS}

Blood lead levels (BLLs) obtained for the entire sample $(\mathrm{n}=308)$ ranged from 0.4 to $65 \mu \mathrm{g} / \mathrm{dl}$ of blood. BLLs for individuals in the study areas meant for environmental assessment ranged from 1.4 to $22.0 \mu \mathrm{g} / \mathrm{dl}$. The lowest, highest and means $\pm 1 \mathrm{SD}$ BLLs in $\mu \mathrm{g} / \mathrm{dl}$ obtained for respective areas were: Kariobangi North $(1.4,22.0,5.0 \pm 3.6)$, Babadogo $(1.5,21.8,5.8 \pm 4.1)$, Waithaka $(1.4,13.0,4.1 \pm 2.7)$ and Pumwani $(3.5,20.3,8.4 \pm 3.8)$. In order of increasing prevalence, those with BLLs $\geq 10 \mu \mathrm{g} / \mathrm{dl}$ were $5.8 \%$ in Waithaka, 10\% in Kariobangi North, $15.2 \%$ in Babadogo and $30 \%$ in Pumwani. The mean BLL for the occupationally exposed (Ziwani Jua kali) was $22.6 \pm 13.4 \mu \mathrm{g} / \mathrm{dl}$ while the lowest and highest BLLs obtained in this group were 5.8 and $65 \mu \mathrm{g} / \mathrm{dl}$ respectively. Eighty nine per cent of the study subjects had BLLs above $10 \mu \mathrm{g} / \mathrm{dl}$. The covariate group at Olkalou had the lowest blood lead concentrations and the levels differed significantly $(p<0.001)$ from those recorded in other study areas. The covariate group at Olkalou had a mean BLL of $1.3 \pm 0.9 \mu \mathrm{g} / \mathrm{dl}$. The lowest BLLs recorded in Olkalou were $0.4 \mu \mathrm{g} / \mathrm{dl}$ and the highest $4.1 \mu \mathrm{g} / \mathrm{dl}$ (Table 1).

Major occupational activities that contributed to the observed BLLs at Ziwani Jua kali works were spray painting $(n=21)$, panel beating $(n=11)$, gas/electrical welding $(\mathrm{n}=7)$ and motor vehicle

Table 1

Blood lead levels in the total sample and prevalence of BLLs $\geq 10 \mu \mathrm{g} / \mathrm{dl}$

\begin{tabular}{|c|c|c|c|c|c|c|}
\hline Region & No. & Mean $\pm 1 S D$ & Mode & Min & Max & $\% \geq 10 \mu \mathrm{g} / \mathrm{dl}$ \\
\hline Kariobangi North & 90 & $5.0 \pm 3.6$ & 2.7 & 1.4 & 22.0 & 10.0 \\
\hline Babadogo & 46 & $5.8 \pm 4.1$ & 3.6 & 1.5 & 21.8 & 15.2 \\
\hline Waithaka & 52 & $4.1 \pm 2.7$ & 2.7 & 1.4 & 13.0 & 5.8 \\
\hline Pumwani & 30 & $8.4 \pm 3.8^{\mathrm{af}}$ & 8.3 & 3.5 & 20.3 & 30.0 \\
\hline Ziwani Jua Kali & 55 & $22.6 \pm 13.4^{\text {bdgi }}$ & 21.2 & 5.8 & 65.0 & 89.1 \\
\hline Olkalou & 35 & $1.3 \pm 0.9^{\text {cehjk }}$ & 0.8 & 0.4 & 4.1 & 0.0 \\
\hline Total & 308 & $8.0 \pm 9.4$ & 3.5 & 0.4 & 65.0 & 25.0 \\
\hline
\end{tabular}

The values are expressed as BLL means \pm standard deviation in $\mu \mathrm{g} / \mathrm{dl} .{ }^{\mathrm{a}}=\mathrm{p}<0.01$ between Kariobangi North and Pumwani; ${ }^{b}=\mathrm{p}<0.001$ between Kariobangi North and Ziwani; ${ }^{\mathrm{c}}=\mathrm{p}<0.001$ between Kariobangi North and Olkalou; ${ }^{\mathrm{d}}=\mathrm{p}<0.001$ between Babadogo and Ziwani; ${ }^{\mathrm{e}}=\mathrm{p}<0.001$ between Babadogo and Ziwani; ${ }^{\mathrm{f}}=\mathrm{p}<0.001$ between Waithaka and Pumwani; ${ }^{g}=p<0.001$ between Waithaka and Ziwani; ${ }^{\mathrm{h}}=\mathrm{p}<0001$ between Waithaka and Olkalou; ${ }^{\mathrm{i}}=\mathrm{p}<0.05$ between Pumwani and Ziwani; ${ }^{\mathrm{j}}=\mathrm{p}<0.01$ between Pumwani and Olkalou; ${ }^{\mathrm{k}}=\mathrm{p}<0.001$ between Ziwani and Olkalou. 
mechanics $(n=8)$. The mean blood lead levels were recorded as $18.1 \pm 4.2 \mu \mathrm{g} / \mathrm{dl}$ for others (general businessmen, hawkers and milk vendors) and 25.3 $\pm 17.8 \mu \mathrm{g} / \mathrm{dl}$ for welders. Painters, panel beaters and those dealing with both spray painting and panel beating had mean BLLs of $21.8 \pm 11.6,22.4 \pm 14.2$ and $24.1 \pm 12.7$ respectively. Eleven per cent of the workers whose blood lead levels were determined had BLLs below $10 \mu \mathrm{g} / \mathrm{dl}$. Forty four per cent of the subjects had levels above $20 \mu \mathrm{g} / \mathrm{dl}$. There was no significant difference $(p>0.05)$ between the BLLs obtained for the various occupations (Table 2).

Agewise, the highest mean BLL $(9.7 \pm 5.7 \mu \mathrm{g} / \mathrm{dl})$ was recorded at Babadogo for the age group $\leq 10$ years while the lowest mean $(2.8 \pm 1.0 \mu \mathrm{g} / \mathrm{dl})$ was recorded at Waithaka for the age set 31-40 years. No significant variation $(p>0.05)$ in BLLs was recorded in Olkalou between the various age sets. A decreasing trend in BLLs with increase in age up to 50 years (Figure 1) was noted for Waithaka, Kariobangi North and Babadogo.
Comparison of blood lead levels for all adults $(>20$ years), showed that the blood lead concentrations obtained at Olkalou differed significantly $(p<0.05)$ with BLLs obtained for all adults in Nairobi. Likewise, blood lead concentrations in Ziwani differed significantly $(\mathrm{p}<0.001)$ with blood lead levels obtained in all the other study areas. There was no significant difference $(\mathrm{P}>0.05)$ in BLLs obtained in Waithaka, Kariobangi North and Babadogo for adults. A comparison of the BLLs obtained within the study areas between individuals below 20 years and those above 20 years indicated no significant variation ( $p>0.05)$ in the BLLs obtained at Kariobangi North, Babadogo, Waithaka, Olkalou and Ziwani. While, BLLs obtained for individuals $<20$ years in Pumwani differed significantly $(\mathrm{p}<0.05)$ with those above 20 years in Kariobangi North, Waithaka and Olkalou, no significant variation ( $p>0.05$ ) was noted between Pumwani and Babadogo as well as Ziwani. BLLs for study subjects aged below 20 years in Ziwani varied significantly $(p<0.05)$ to the blood lead values

Table 2

Blood lead levels $(\mu \mathrm{g} / \mathrm{dl})$ in Ziwani Jua kali

\begin{tabular}{lcccccc}
\hline Occupational activity & No. & Mean \pm ISD & Median & Min. & Max. & $\%>10 \mu \mathrm{g} / \mathrm{dl}$ \\
\hline Painters & 21 & $21.8 \pm 11.6$ & 21.2 & 10 & 65 & 100 \\
Welders & 7 & $25.3 \pm 17.8$ & 17.0 & 11.2 & 58.2 & 100 \\
Painters/ panel beaters & 3 & $24.1 \pm 12.7$ & 22.3 & 12.4 & 37.6 & 100 \\
Panel beaters & 11 & $22.4 \pm 14.2$ & 18.3 & 7.9 & 50.8 & 72.7 \\
Mechanics & 8 & $23.0 \pm 19.0$ & 13.9 & 5.8 & 52.9 & 62.5 \\
Others & 5 & $18.1 \pm 4.2$ & 18.6 & 11.3 & 21.7 & 100 \\
\hline Total & 55 & $22.5 \pm 13.4$ & 18.6 & 5.8 & 65 & 89.2 \\
\hline
\end{tabular}

Figure 1

Mean blood lead level $(\mu \mathrm{g} / \mathrm{dl})$ concentrations by age

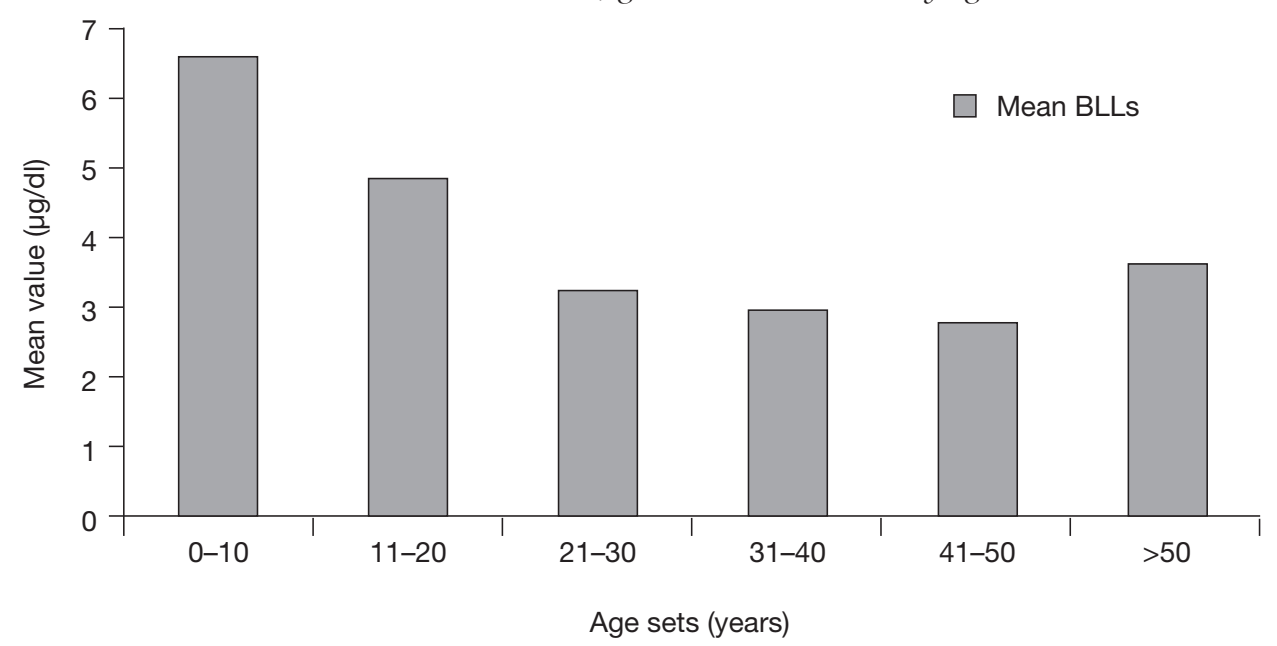


obtained for individuals above 20 years in Kariobangi North, Babadogo, Waithaka and Olkalou.

One hundred and twenty six subjects in the entire study sample aged 20 years and below had blood lead levels ranging from 0.4 to $35.6 \mu \mathrm{g} / \mathrm{dl}$. Thirty six children and adolescents in Kariobangi North, twenty six in Babadogo, twenty in Waithaka and thirty in Pumwani had BLLs ranging from 1.4 to $21.8 \mu \mathrm{g} / \mathrm{dl}$. The lowest and highest BLLs $(\mu \mathrm{g} / \mathrm{dl})$ obtained for individual study areas in Nairobi for children and adolescents were recorded as: Kariobangi North (2.1; 16.5), Babadogo (1.5; 21.8), Waithaka $(1.4 ; 13.0)$ and Pumwani $(3.5 ; 20.3)$. Mean \pm 1SD BLLs recorded for children and adolescents were $6.3 \pm 3.7,7.3 \pm 4.8,5.1 \pm$ 3.4 and $8.4 \pm 3.8 \mu \mathrm{g} /$ dl for Kariobangi North, Babadogo, Waithaka and Pumwani, respectively. Five (9\%) of the occupationally exposed study subjects were equal to or below 20 years of age and all had BLLs above $15 \mu \mathrm{g} / \mathrm{dl}$. Actual BLLs obtained for the five were 35.6, 22.1, 15.7, 27.0 and $21.7 \mu \mathrm{g} / \mathrm{dl}$ and the mean was $24.4 \pm 7.4 \mu \mathrm{g} / \mathrm{dl}$. In order of increasing prevalence, individuals aged 20 years and below whose blood lead levels exceeded $10 \mu \mathrm{g} / \mathrm{dl}$ and $5 \mu \mathrm{g} / \mathrm{dl}$ in specific study areas meant for assessment of environmental exposure in Nairobi were Waithaka $(10 \%, 40 \%)$, Kariobangi North $(17 \%$, $44 \%)$, Babadogo $(27 \%, 62 \%)$ and Pumwani $(30 \%, 83 \%)$, respectively (Table 3 ).

Table 4 shows the mean BLLs grouped in age categories ( $\leq 5,6-10,11-15$ and $16-20$ years) for the study subjects aged 20 years and below. Mean BLLs ranged from 4.1 to $10.6 \mu \mathrm{g} / \mathrm{dl}$. The lowest and highest means $(\mu \mathrm{g} / \mathrm{dl})$ for individual study areas in Nairobi were: Kariobangi North $(4.1 \pm 0.2,8.7 \pm$ 4.5), Babadogo $(5.2 \pm 3.1,10.6 \pm 5.9)$ and Waithaka $(3.3 \pm 0.1,7.1 \pm 4.0)$. Only two age categories: $6-10$ and 11-15 years were identified for Pumwani and their mean BLLs were recorded as $7.9 \pm 3.7$ and 8.5 $\pm 3.9 \mu \mathrm{g} / \mathrm{dl}$ respectively. In Olkalou, the means for the age categories were almost the same with the lowest mean being $0.9 \pm 0.6 \mu \mathrm{g} / \mathrm{dl}$ and the highest $1.7 \pm 1.1 \mu \mathrm{g} / \mathrm{dl}$. The occupationally exposed that were aged 16 to 20 years had a mean of $24.4 \pm 7.4 \mu \mathrm{g} / \mathrm{dl}$.

Table 3

Blood lead levels $(\mu \mathrm{g} / \mathrm{dl})$ for individuals' aged $\leq 20$ years in the total sample

\begin{tabular}{lccccccc}
\hline Area of study & No. & Mean $\pm 1 \mathrm{SD}$ & Mode & $\%>10 \mu \mathrm{g} / \mathrm{dl}$ & $\%>5 \mu \mathrm{g} / \mathrm{dl}$ & Min. Bll & Max. Bll \\
\hline Kariobangi North & 36 & $6.3 \pm 3.7$ & 4.5 & 17.0 & 44.0 & 2.1 & 16.5 \\
Babadogo & 26 & $7.3 \pm 4.8$ & 3.6 & 27.0 & 62.0 & 1.5 & 21.8 \\
Waithaka & 19 & $5.1 \pm 3.4$ & 3.2 & 10.0 & 40.0 & 1.4 & 13.0 \\
Pumwani & 30 & $8.4 \pm 3.8$ & 8.3 & 30.0 & 83.0 & 3.5 & 20.3 \\
Ziwani Jua Kali & 5 & $24.4 \pm 7.4^{\mathrm{c}}$ & $\mathrm{N} / \mathrm{A}$ & 100.0 & 100.0 & 15.7 & 35.6 \\
Olkalou & 10 & $1.5 \pm 1.0^{\text {abde }}$ & 0.8 & 0.0 & 0.0 & 0.4 & 3.8 \\
\hline
\end{tabular}

The values are expressed as BLL means \pm standard deviation in $\mu \mathrm{g} / \mathrm{dl} .{ }^{\mathrm{a}}=\mathrm{p}<0.01$ between Kariobangi North and Olkalou; ${ }^{\mathrm{b}}=\mathrm{p}<0.01$ between Babadogo and Olkalou; ${ }^{\mathrm{c}}=\mathrm{p}<0.05$ between Waithaka and Ziwani; $\mathrm{d}=\mathrm{p}<0.001$ between Pumwani and Olkalou; ${ }^{\mathrm{e}}=\mathrm{p}<0.001$ Olkalou and Ziwani.

Table 4

Mean $\pm 1 S D(\mu \mathrm{g} / \mathrm{dl})$ blood lead levels by age sets for subjects aged $\leq 20$ years

\begin{tabular}{|c|c|c|c|c|}
\hline Area/age (years) & $0-5(n=16)$ & $6-10(\mathrm{n}=34)$ & $11-15(\mathrm{n}=42)$ & $16-20(\mathrm{n}=34)$ \\
\hline Kariobangi North & $8.7 \pm 4.5(\mathrm{n}=8)$ & $6.6 \pm 3.1(n=13)$ & $4.1 \pm 0.2(n=5)$ & $5.3 \pm 3.3(n=10)$ \\
\hline Babadogo & $6.2 \pm 3.6(n=2)$ & $10.6 \pm 5.9(\mathrm{n}=8)$ & $5.2 \pm 3.1(\mathrm{n}=10)$ & $6.8 \pm 4.3(n=6)$ \\
\hline Waithaka & $7.1 \pm 4.0(\mathrm{n}=4)$ & $5.8 \pm 3.0(n=3)$ & $3.3 \pm 0.1(n=2)$ & $4.4 \pm 3.7(n=11)$ \\
\hline Pumwani & & $7.9 \pm 3.7(n=5)$ & $8.5 \pm 3.9(n=25)$ & \\
\hline Olkalou & $1.0 \pm 0.69(\mathrm{n}=2)$ & $1.7 \pm 1.1^{\mathrm{a}}(\mathrm{n}=5)$ & & $0.9 \pm 0.6(\mathrm{n}=2)$ \\
\hline Ziwani & & & & $24.4 \pm 7.4^{\mathrm{abcd}}(\mathrm{n}=5)$ \\
\hline
\end{tabular}

The values are expressed as BLL means \pm standard deviation in $\mu \mathrm{g} / \mathrm{dl} .^{\mathrm{a}}=\mathrm{p}<0.01$ between Babadogo and Olkalou age sets 6-10 years: $p<0.001$ between Kariobangi North and Ziwani for the age category 16-20 years; $^{b}=\mathrm{p}<0.001$ between Babadogo and Ziwani for individuals of $16-20$ years; ${ }^{c}=p<0.001$ between Waithaka and Ziwani for individuals of 16-20 years; ${ }^{\mathrm{d}}=\mathrm{p}<0.001$ between Olkalou and Ziwani for individuals aged 16-20 years. 
Table 5

Blood lead levels for children aged $\leq 10$ years in Nairobi and Olkalou

\begin{tabular}{lcccc}
\hline Area of study & No. & Mean \pm 1 SD & $\%>10 \mu \mathrm{g} / \mathrm{dl}$ & $\%>5 \mu \mathrm{g} / \mathrm{dl}$ \\
\hline Kariobangi North & 21 & $7.4 \pm 3.9$ & 24 & 61.9 \\
Babadogo & 10 & $9.7 \pm 5.7$ & 50 & 70 \\
Waithaka & 7 & $6.5 \pm 3.0$ & 14.2 & 71 \\
Pumwani & 5 & $7.9 \pm 3.7$ & 40 & 60 \\
Olkalou & 7 & $1.7 \pm 1.1^{\mathrm{ab}}$ & nil & nil \\
\hline
\end{tabular}

The values are expressed as BLL means \pm standard deviation in $\mu \mathrm{g} / \mathrm{dl} .{ }^{\mathrm{a}}=\mathrm{p}<0.05$ between Kariobangi North and Olkalou age sets 6-10 years; ${ }^{\mathrm{b}}=\mathrm{p}<0.01$ between Babadogo and Olkalou.

Table 5 presents mean blood lead levels for study subjects aged ten years and below. Thirty two per cent of the children $\leq 10$ years had BLLs exceeding $10 \mu \mathrm{g} / \mathrm{dl}$. In individual study areas within Nairobi, the mean BLLs and per centage of children in this age category with BLLs greater than $10 \mu \mathrm{g} / \mathrm{dl}$ in ascending order, were reported as: Waithaka (6.5 $\pm 3.0 ; 14.2 \%)$, Kariobangi North $(7.4 \pm 3.9 ; 24 \%)$, Pumwani $(7.9 \pm 3.7 ; 40 \%)$ and Babadogo (9.7 \pm 5.7 ; $50 \%$ ). Sixty five per cent of the children in Kariobangi North, Babadogo, Pumwani and Waithaka aged less than 10 years had levels above $5 \mu \mathrm{g} / \mathrm{dl}$ while in Olkalou, no individual exceeded this level.

\section{DISCUSSION}

In this study, blood lead levels (BLLs) were determined in consenting individuals and a comparison of the obtained BLLs done between the selected areas in Nairobi and Olkalou in Nyandarua district to assess both general population and occupational exposures to lead. BLLs obtained for Nairobi study areas of Kariobangi North, Babadogo, Waithaka and Pumwani were compared to levels obtained in Olkalou for the purpose of environmental assessment. Occupational lead exposure evaluation was done by determination of BLLs in Jua kali workers at Ziwani in Nairobi. Mean blood lead levels obtained for a respective study area constitutes the baseline BLLs and an indication of the status of lead exposure in that particular region. The results of this study indicates $25 \%$ of the entire study populations had BLLs above $10 \mu \mathrm{g} / \mathrm{dl}$ and hence exposed to unacceptable levels of lead either environmentally and/or occupationally. However, geographical distribution of BLLs obtained, largely indicated non-exposure in Olkalou where none of the study subjects had levels above $10 \mu \mathrm{g} / \mathrm{dl}$ as opposed to Nairobi where significant exposure is indicated with $15 \%$ of the population having elevated blood lead levels. A distinction between levels of exposure environmentally and occupationally is clearly shown.

The prevalence of lead poisoning in Nairobi shifted from low to high, on a rural-urban to urban trend and the levels may be higher in the inner side of Nairobi City. Blood lead levels obtained at Pumwani were significantly elevated than those found in other study areas within Nairobi. A major predictor of elevated BLLs in this area can be attributed to exposure to airborne lead emissions from vehicles. The significance $(\mathrm{p}<0.05)$ variation in BLLs obtained between Pumwani and other areas; Kariobangi and Waithaka indicated increased exposure to environmental lead relative to proximity to the central business district. Thirty per cent of the children whose blood lead levels were determined at Pumwani had BLLs above $10 \mu \mathrm{g} / \mathrm{dl}$ as compared to $17 \%$ and $10 \%$ in Kariobangi and Waithaka, respectively. The levels obtained for children are a clear indicator that a big proportion of children could be exposed to high levels of lead in the environment. Of major concern is the indication that $15.6 \%$ of children below five years of age and $32 \%$ of children below 10 years had levels above $10 \mu \mathrm{g} / \mathrm{dl}$. Equally, the trend in blood lead levels in relation to age, indicates that children are more susceptible to lead exposure and having high deposition and retention rates than adults.

The results obtained for the Nairobi study were lower than those reported in South Africa $(15,16)$. The South Africa study was carried out on a total of 1287 children in the Cities of Johannesburg $(n=382)$, Capetown $(n=429)$ and Kimberley $(n=355)$, remote rural towns of Pella and Onseepkans $(n=119)$ and a lead mining town of Aggeneys $(n=21)$. The study in South Africa reported blood lead levels in children ranging from $1.0-44.4 \mu \mathrm{g} / \mathrm{dl}$ (mean $6.9 \pm 3.27 \mu \mathrm{g} / \mathrm{dl}$ ) 
compared to the levels of children ( $\leq 20$ years) in Nairobi that ranged from 1.4 to $21.8 \mu \mathrm{g} / \mathrm{dl}$ (mean $=$ $7.7 \mu \mathrm{g} / \mathrm{dl})$. The prevalence of children above $10 \mu \mathrm{g} / \mathrm{dl}$ and $5 \mu \mathrm{g} / \mathrm{dl}$ in South Africa was reported as $17 \%$ and $78 \%$ respectively while in Nairobi, $21 \%$ and $57.3 \%$ of children had levels above $10 \mu \mathrm{g} / \mathrm{dl}$ and $5 \mu \mathrm{g} / \mathrm{dl}$, respectively. Blood lead levels for younger children ( $\leq 10$ years) in Nairobi ranged from 2.6 to $21.6 \mu \mathrm{g} / \mathrm{dL}$ and the proportion above $10 \mu \mathrm{g} / \mathrm{dl}$ was $32 \%$, an indication of less poisoning in Nairobi than in South Africa. By individual study sites, mean BLL, peak BLL and the per centage of the population above $10 \mu \mathrm{g} / \mathrm{dl}$ in individual study sites obtained in Kariobangi North, Babadogo, Waithaka and Pumwani were lower than those reported in Johannesburg (9.1 \pm $3.1 \mu \mathrm{g} / \mathrm{dl} ; 44.4 \mu \mathrm{g} / \mathrm{dl} ; 35 \%)$, Capetown $(6.4 \pm 2.9 \mu \mathrm{g} / \mathrm{dl}$; $24.5 \mu / \mathrm{g} / \mathrm{dl} ; 10 \%)$, Kimberley $(7.1 \pm 2.7 \mu \mathrm{g} / \mathrm{dl} ; 22.6 \mu \mathrm{g} /$ dl; $10 \%)$, Pella and Onseepkans $(6.1 \pm 2.5 \mu \mathrm{g} / \mathrm{dl}$; $17.1 \mu \mathrm{g} / \mathrm{dl} ; 7.6 \%)(15,16)$.

Comparatively, the findings in Nairobi indicated high level of exposure in Nairobi for children aged $\leq 10$ years than a multinational study carried out in the Middle East in the period 1996-2000 (17). Apart from vehicular emission, the study which was carried out in Israel, Westbank, Gaza and Jordan to assess childhood lead poisoning, identified other sources of exposure to be releases from industries such as smelters, battery factories and radiator shops, burning of solid wastes and flour from traditional stone mills. While the study in Nairobi reported a prevalence of $32 \%$ of children aged $\leq$ ten years as having blood lead levels above $10 \mu \mathrm{g} / \mathrm{dl}$, highest levels reported in the Middle East were noted in Gaza $(n=435)$ where a mean level of $8.6 \mu \mathrm{g} / \mathrm{dl}$ was obtained and $17.2 \%$ of children had levels above $10 \mu \mathrm{g} / \mathrm{dl}$.

The results in Nairobi indicated a great risk of lead overexposure to workers. The high prevalence rate of workers having BLLs above $10 \mu \mathrm{g} / \mathrm{dl}$ at the Jua Kali works is a clear indication of an urgent need to address occupational exposure. Some of the workers had levels $\geq 40 \mu \mathrm{g} / \mathrm{dl}$ which warranted removal from work; the risks of developing renal insufficiency and other complications was high in five of the workers who had levels of 65, 58.2, 52.9, 50.8 and $42.8 \mu \mathrm{g} / \mathrm{dl}$. Major source of exposure can be attributed to paint as evidenced by the levels obtained for spray painters who had a mean of $21.8 \mu \mathrm{g} / \mathrm{dl}$. The high exposure to the workers could also be attributed to lack of knowledge concerning lead and the danger to their health, poor working conditions, and lack of protective gear. While the environment within the spraying chamber exposes the workers to high concentration of lead in paint, spraying in the area exposes all within the vicinity due to dissemination of aerosols into a wide area.

The variations in blood lead levels observed between the occupationally and non-occupationally exposed groups in Nairobi, although at higher levels, are similar to what Ferah et al (18) reported in a study carried out in Turkey. The study on 39 adolescent workers in an auto repair workshop who included auto electricians, repairmen, painters and bonnet straighters, 13 adults in a battery production unit and a rural covariate group $(n=29)$, reported the levels for the auto repair workers (mean: $8.13 \pm$ $7.41 \mu \mathrm{g} / \mathrm{dl}$ ) to be significantly higher than the rural population (mean: $3.49 \pm 1.39 \mu \mathrm{g} / \mathrm{dl}$ ).

In conclusion, this study achieved its major objective of determining the status of general public and occupational exposure to lead in selected parts of Nairobi, Kenya and provided baseline blood lead levels. It is recommended, based on the findings, that intervention measures to protect the general population and workers from over exposure to lead, should be instituted. Likewise, a detailed study to determine and evaluate all sources of lead and their contribution to lead exposure should be done. A general public screen on lead exposure and regular screening of the public living in high risk areas and workers will promote prevention and reduction of lead exposure and early diagnosis and are recommended. The establishment of a permanent centre to deal with lead poisoning and other environmental toxicants is recommended. Such a facility should have the capacity to diagnose, treat and manage lead poisoning, assess occupational and environmental sources of lead exposure and be a resource centre. Preventive measures in occupational setups should include: workers education; instruction on personal hygiene techniques and preventive strategies, establishment of engineering controls, provision of personal protective equipment, protective clothing and face masks, gloves e.t.c. Environmental lead exposure can be prevented and greatly reduced by regulation of emissions from vehicles, mining, smelting and refining operations which effectively reduce atmospheric lead, replacing water delivery pipes with non-lead plumbing, establishment of 
good manufacturing practices for lead such as use of acid resistant ceramic ware which reduces lead entering food through cooking utensils and canned food.

\section{ACKNOWLEDGEMENTS}

The United Nations Environmental Programme (UNEP) in Nairobi collaborated in this study and provided a blood lead analyzer from the United States Environmental Protection Agency (USEPA) and finances from the Partnership for Cleaner Fuels and Vehicles (IPCFV) and collectively, the authors greatly acknowledge their contributions. Dr. A.E. Ogwell, then Head, Division of Non-communicable diseases at the Ministry of Health (Kenya) and the entire staff provided enormous logistical support which is highly appreciated. Many thanks go to Dr. D.N. Nguku, MOH-Nairobi City Council and staff of the various health centres for their support and participation. Much appreciation is also accorded to all the children and adults who participated in this study and the entire community of the St. John community centre in Pumwani and all the workers of Ziwani "Jua Kali" engineering works. The $\mathrm{MOH}$, Olkalou District Hospital and residents of Olkalou and the dedicated research team of C. Kibiti (Kenyatta University), J. Mukaya and A. Gathoni both of Kenyatta National Hospital were instrumental for the success of the study and their contributions are appreciated. We also thank G.G. Michuku for statistical analysis.

\section{REFERENCES}

1. Agency for Toxic Substances and Disease Registry (ATSDR). Toxicological profile for lead. (Draft for Public Comment) Atlanta, GA: US Department of Health and Human Services, Public Health Service. 2005. www.atsdr.cdc.gov.

2. United States Environmental Protection Agency (USEPA). Air Quality Control for Lead: Supplement to the 1986 Addendum. Environmental Criteria and Assessment Office, Research Triangle Park.NC.EPA600/8-89/049F. 1990. http://www.epa.gov/

3. Tong, S., Yasmin, E., von Schirnding, Y.E.R. and Prapamontol T. Environmental lead exposure: A public health problem of global dimensions. Bull. WHO. 2000; 78: 1068-1074.

4. Mushak, P. Defining lead as the premier environmental health issue for children in America. Criteria and their quantitative application. Environ. Res. 1992; 59: 281-309.
5. International Programme on Chemical Safety. Inorganic lead. Environmental health criteria 165. Geneva: World Health Organisation 1995.

6. Lead. In: Children's Health and the Environment. WHO training package for the health sector. World Health Organisation 2005. www.who.int/ceh.

7. Centres for Disease Control and Prevention (CDC). Screening young children for lead poisoning: guidance for state and local public health officials. Atlanta: US Department of Health and Human Services. 1991. http://www.cdc.gov/

8. Poklis, A., Wong, S.H.Y. and Pesce A.J. Toxicology. In: Kaplan, L.A., Pesce, A.J., editors. Clinical chemistry: Theory, analysis and correlation. 3rd edn. Mosby-Year Book, inc. 1996; 1017-1030.

9. Plaa, G.L. Introduction to toxicology: Occupational and environmental. In: Katzung, B.G., editor. Basic and Clinical Pharmacology. $8^{\text {th }}$ edn. Lange Medical Books / McGraw-Hill 2001; 987-997.

10. Kosnett, M.J. Heavy metal intoxication and chelators. In: Katzung, B.G. editor. Basic and clinical pharmacology; $8^{\text {th }}$ edn. Lange Medical Books/ McGraw-Hill 2001; 999-1002.

11. Centres for Disease Control and Prevention (CDC). Preventing lead poisoning in young children: A statement by the Centres for Disease Control and Prevention. Atlanta, USA. 2005 http://www.cdc.gov/.

12. Lanphear, B.P., Dietrich, K.N., Auinger, P. and Cox C. Cognitive deficits associated with blood lead levels concentrations $<10 \mu \mathrm{g} / \mathrm{dl}$ in US children and adolescents. Public Health Rep. 2000; 115: 521-529.

13. Canfield, R.L., Henderson, C.R., Cory-Sletchta, D.A., et al. Intellectual impairment in children with blood lead levels below $10 \mu$ g per deciliter. N. Engl. J. Med. 2003; 348: 1517-1526.

14. ESA LeadCare ${ }^{\circledR}$ Blood lead testing system user's guide.

15. Mathee, A., von Schirnding, Y.E.R., Levine, J., et al. A survey of blood lead levels amongst young Johannesburg school children. Environ. Res. 2002; 90: 181-184.

16. von Schirnding, Y.E.R., Mathee, A., Robertson, P., et al. Distribution of blood lead levels in school children in selected Cape Peninsula suburbs subsequent to reductions in petrol lead. South Afr. Med. J. 2001; 91: 870-872.

17. Safi, J., El-haji, S., Sansour, R., et al. Childhood lead exposure in Palestinian Authority, Israel and Jordan: Results from the Middle Eastern regional cooperation project 1996-2000. Environ. Health Perspect. http://dx.doi. org/accessed $24^{\text {th }}$ January 2006.

18. Ferah, S., Osman, D., Hulk, M.O., et al. Lead exposure and urinary $\mathrm{N}$-acetyl- $\beta \sim \mathrm{D}$-glucosaminidase activity in adolescent workers in auto repair workshop. J. Adolesc. Health. 2002; 30: 213-216. 